\title{
Up-Regulating Telomerase and Tumor Suppression: A Two-Step Strategy to Boost Hematopoietic Stem Cell Transplantation
}

Fernando Pires Hartwig

Postgraduate Program in Epidemiology, Department of Social Medicine, Faculty of Medicine, Federal University of Pelotas, Brazil

\begin{abstract}
The high levels of morbidity and mortality of chronic non-communicable diseases (most of which highly associated with aging) worldwide indicate the need of studying the underlying mechanisms of physiological aging and aging related-impairments, as well as developing and improving therapeutic approaches such as cell therapy. In this manuscript, two well-established aging mechanisms - telomere shortening and DNA damage accumulation - are briefly reviewed regarding their roles in hematopoietic stem cells function and transplantation. Based on the available literature, up-regulating both telomerase and tumor suppression responses is proposed in a two-step strategy as a promising mechanism to benefit hematopoietic stem cell transplantation qualitatively (by enriching the cell pool for healthy hematopoietic stem cells) and quantitatively (by in vitro expansion of healthy hematopoietic stem cells). The applications, limitations and perspectives associated with the proposed strategy are also discussed.
\end{abstract}

Keywords: Telomere length; Telomerase; DNA damage; Tumor suppression; Hematopoietic stem cells

Abbreviations: ASCs: Adult Stem Cells; HSCs: Hematopoietic Stem Cells; HSCT: Hematopoietic Stem Cell Transplantation

\section{Introduction}

The recent trends in the age structure of most populations worldwide has changed the scenario of common causes of morbidity and mortality, with chronic non-communicable diseases (e.g., cardiovascular diseases, cancer and diabetes) featuring as (or among) the most frequent ones [1]. Currently, such diseases are considered a public health concern, indicating the importance of elucidating the mechanisms implicated in physiological aging and aging-related impairments. Such elucidation may contribute to the development and improvement of new therapeutic strategies for age-related diseases, with cell therapy featuring among the most promising approaches [2]. Regarding aging physiology and associated diseases, telomere biology is among the most relevant molecular mechanisms [3]. Briefly, telomeres are guanine-rich (5' TTAGGG 3' in humans) DNA tandem repeats located at the end of eukaryotic chromosomes [4] associated with at least six proteins, (called shelterin) which compose the telomeric structure [5]. The telomeres have several important roles, such as preventing both the recognition of chromosome ends as sites of DNA damage and the occurrence chromosome end fusions [6]. An important aspect of telomere biology is that the telomeres are shortened after a cell division due to the end replication problem (i.e., the incapacity of the replication machinery to replicate the ends of eukaryotic chromosomes) [7], resulting in telomere dysfunction with time. Since telomere dysfunction elicits tumor suppression responses, critical telomere shortening results in loss of cell viability by either senescence or apoptosis [8].

In spite of telomere shortening being a natural consequence of DNA replication, telomerase activity counteracts the end replication problem by promoting reverse transcription-based telomere lengthening. Telomerase is a ribonucleoprotein enzymatic complex composed by two main subunits: the telomerase reverse transcriptase (the catalytic subunit, encoded by TERT in humans and Tert in mice GeneEntrezIDs: 7015 and 21752, respectively) and the telomerase RNA component (the RNA template for reverse transcription, encoded by TERC in humans and Terc in mice - GeneEntrezIDs: 7012 and 21748, respectively) $[9,10]$. The relevance of telomere biology (especially of telomerase) for human health and disease is such that the 2009 Nobel Prize in Medicine and Physiology was awarded to telomerase discoverers [11]. Telomerase activity is present in primitive cell types, such as embryonic stem cells, germline stem cells and adult stem cells (ASCs) [12-14]. In the last, however, telomerase activity is sufficient only to delay telomere shortening $[15,16]$, thus resulting in ASCs eventually reaching a critical telomere length state after several cell divisions. Given the importance of ASC to maintain homeostasis by allowing tissue self renewal during the lifespan, telomere-related ASC exhaustion is currently among the best established aging mechanisms. In disease, telomerase activity plays a major role in cancer, being present in $85-90 \%$ of human cancers $[17,18]$. This makes telomerase one of the most prevalent cancer makers and indicates that telomerase activation is the most frequent mechanism of replicative immortality. It is important to note, however, that telomerase activity is commonly regarded as a consequence of genetic instability rather than an early event in the carcinogenic process. Interestingly, telomere dysfunction is considered an early cancer event that is highly associated with genetic instability [19], indicating that telomere length/integrity, telomerase activity and tumor suppression responses interact in a complex fashion, which may regulate their association with ASC impairment and cancer [20].

\section{Telomere Biology in Hematopoietic Stem Cell Physiology and Transplantation}

Considering the importance of telomere biology for tissue self-

*Corresponding author: Fernando Pires Hartwig, Postgraduate Program in Epidemiology, Department of Social Medicine, Faculty of Medicine, Federal University of Pelotas, Brazil, Tel: (5553) 81347172; E-mail: fernandophartwig@gmail.com

Received July 02, 2013; Accepted September 11, 2013; Published September 13,2013

Citation: Hartwig FP (2013) Up-Regulating Telomerase and Tumor Suppression: A Two-Step Strategy to Boost Hematopoietic Stem Cell Transplantation. J Stem Cell Res Ther S3:003. doi:10.4172/2157-7633.S3-003

Copyright: (c) 2013 Hartwig FP. This is an open-access article distributed unde the terms of the Creative Commons Attribution License, which permits unrestricted use, distribution, and reproduction in any medium, provided the original author and source are credited. 
renewal by regulating ASC viability, it is intuitive that telomereassociated diseases are most prominently manifested in high turnover tissues, such as the skin and the blood. In the hematopoietic compartment the cell turnover is estimated around $10^{9}$ cells produced per hour [21] and is known to be highly dependent on hematopoietic stem cells (HSCs) [22]. In telomere syndromes (phenotypes - normally a disease-related state - caused by genetic profiles associated with telomere biology [23]) such as dyskeratosis congenita, blood-related manifestations are particularly common, being bone marrow failure the most common cause of death (approximately 60\% to $70 \%$ of cases) [24]. These manifestations are well-characterized consequences of HSC exhaustion due to premature critical telomere shortening, resulting in dyskeratosis congenita being considered a stem cell disease [25]. Although dyskeratosis congenita is not a particularly frequent condition, it serves as an useful model for understanding telomere biology implications for disease [26]. Regarding stem cell therapy and tissue engineering, the notion that HSCs are especially dependent on telomere integrity due to their very high turnover strongly suggests that HSC transplantation (HSCT) has the potential to be improved by exploring telomere-related strategies.

There is a number of studies that investigated the roles of telomere biology in HSC. As pointed by others [23], there is solid evidence (from investigations in both humans and mice) that quantitative and qualitative defects in HSCs caused by telomere shortening result in HSC exhaustion, and a significant portion of such evidence came from studies on telomere syndromes [27-33]. Regarding the importance of telomere biology for HSCT, one of the earliest studies provided convincing evidence for telomere shortening in HSC in vivo by doing serial transplantations in murines [34]. In the following year, two studies added further evidence to this notion: one study showed that neutrophil telomere length was shorter in human HSCT recipients (when compared to their donors) at engraftment and 6 and 12 months after HSCT [35]; the other study evidenced, in mice, that stimulated T cells present telomere lengthening by telomerase activity, suggesting that telomerase in HSCs may be important to extend proliferative capacity after transplantation [36]. By this time, the potentially benefic effects of overexpressing TERT to enhance HSC replicative potential during transplantation were already recognized [37] due to the understanding that the limited proliferative potential of HSC associated with short telomeres being a relevant concern regarding ex vivo HSC expansion for therapeutic purposes [38]. A subsequent study reinforced the notion that transplanted HSCs suffer replicative stress due to telomere shortening, resulting in accelerated senescence [39]. In addition, two key studies provided direct evidence for the potential of telomerase activation to improve HSCT. By comparing wild type and telomerase-deficient mice donors, it was shown that telomerase allows HSC to be viable after more rounds of serial transplantation and that telomerase counteracts telomere shortening that occurs during transplantation [30]. The second study overexpressed (using retroviral vectors) TERT in $\mathrm{CD}_{4} 4^{+}$and $\mathrm{AC} 33^{+}$cord blood cells and provided evidence for a role of telomerase in HSC proliferation and differentiation abilities [40].

\section{DNA Damage Implications for Hematopoietic Stem Cells Culture}

It is well evidenced that telomeres and telomerase have major roles in HSC senescence and that such roles can be exploited in clinical applications of HSC by approaches based on telomere biology manipulation in order to delay HSC replicative exhaustion [41]. It is important to note, however, that telomere shortening is not the only mechanism proposed for organism aging, which is currently considered a multifactorial trait [42]. Among such mechanisms there is DNA damage accumulation $[43,44]$, which is of special relevance for this manuscript since it has been studied in HSCs. By observing HSC of mice deficient for different genomic maintenance pathways (including nucleotide excision repair, telomere maintenance and nonhomologous end-joining), it has been shown that accumulated DNA damage functionally impairs HSC (but does not depletes HSC reserves) with age, culminating with HSC functional exhaustion. Evidence for DNA damage accumulation in wild type HSCs has also been provided by this study, indicating that such event occurs physiologically [33]. These findings are in agreement with another study using a mice model for Ligase IV syndrome, which are deficient for DNA double-strand break repair by non-homologous end-joining. Based on their findings, the authors suggested that HSCs sensitivity to non-homologous endjoining deficiency (a conclusion extensible to other types of DNA damage accumulation) is a key factor for HSCs to withstand culture and transplantation [45]. The findings of these studies, which have been corroborated and complemented by additional investigations [46], provide strong evidence for the notion that genomic stress is a causal factor of HSCs aging by limiting their ability to maintain tissue homeostasis [47]. In addition to the diminished capacity of HSC caused by DNA damage accumulation, it is important to note that such event is among the most well-established cancer mechanisms $[48,49]$. This reasoning suggests that in vitro culturing HSCs naturally induces their decay (which is well established by the literature, as discussed in the present text) and may result in accumulation of potentially dangerous characteristics in the context of cancer.

The fact that telomerase is associated with cancer is a significant concern for the use of telomerase activation in cell culture with clinical purposes. As discussed elsewhere [50], there are alternatives to reduce this risk, such as using moderate and transient TERT upregulation by chemical activators instead of lentivirus-based systems and co-treatment with differentiation agents (which would not apply to HSCT). However, it is important to not underestimate the cancer risk associated with telomerase, especially when considering the emerging evidence for non-canonical (i.e., telomere-independent) roles of telomerase in processes such as apoptosis resistance [51,52], DNA damage repair [53] and in cancer-related signaling pathways [54]. Interestingly, TERT up-regulation has also been shown to reduce intracellular reactive oxygen species production [55,56], indicating that telomerase activity stimulation by TERT up-regulation may be accompanied by antioxidant defenses, which has potentially beneficial applications for HSC in vitro culture. Such application is to be cautiously considered, however, since reducing oxidative stress could potentially lead to maintenance of certain injuries/damages that would normally be eliminated from the HSC pool by triggering intracellular reactive oxygen species production that results in cell cycle arrest or death.

\section{A Two-Step Strategy for HSC In Vitro Expansion: A Hypothesis to Boost HSCT}

Tumor suppression responses are known (mostly from cancer research) to be key factors to prevent or reduce DNA damage accumulation along cell divisions [49]. Tumorigenesis is characterized by increased mutability rates, which is significantly favored by compromising the tumor suppression machinery that monitor genomic integrity and detect DNA damage, triggering either senescence or apoptosis [57-59]; and in vivo experiments confirm the implications of such pathways for cancer [60]. Interestingly, tumor 
Citation: Hartwig FP (2013) Up-Regulating Telomerase and Tumor Suppression: A Two-Step Strategy to Boost Hematopoietic Stem Cell Transplantation. J Stem Cell Res Ther S3:003. doi:10.4172/2157-7633.S3-003

suppression responses have been evidenced to prevent (or at least reduce) accumulation of cells with DNA damage within a given ASC pool, since damaged ASCs undergo either senescence or apoptosis [61]. All this evidence supports the notion of up-regulating both telomerase activity and tumor suppression responses in order to increase cell and organism life-span without increasing cancer risk.

Such hypothesis has been addressed in an elegant experiment using mice that overexpressed either Tert (in the epithelia, regulated by Krt5 - GeneEntrezID: 110308 - promoter or tumor suppression genes, and a group that overexpressed both (called the SUPER-M mice) [62], resulting in mice with less aging but no increase in cancer rates [63]. The median survival values (both overall and cancer-free) for each mice group are shown in figure 1. These results, in light of the biology already elucidated, allowed the proposal of new stem cell-based models for aging, focusing on the roles of telomerase and tumor suppression [64]. In fact, the median survival values shown in figure 1 indicate that telomeres and tumor suppression are effect modifiers of each other, since the median survival increase of the SUPER-M mice compared to the control group is greater than the simple addition of the median survival increase due to overexpression of Tert and tumor suppressors individually, also compared to the control group (which can be easily identified by comparing groups 1-3 and 2-4, from top to bottom). This evidence for effect modification strongly suggests that telomerase and tumor suppression interact in a complex fashion [20], and such interaction can be exploited in cell culture with clinical application purposes.

The evidence discussed so far strongly suggests that telomerase activation and tumor suppression have significant implications (either individually and combined, with evidence for interaction between the two mechanisms) for in vitro culturing of HSCs, which is required for many of the potential clinical applications regarding cell therapy. In a two-step strategy to boost HSCT by selecting and expanding healthier (i.e., cells with reduced DNA damage - and other markers of stress - accumulation and with relatively long telomeres) HSCs based on up-regulation of both telomerase activity and tumor suppression responses (Figure 2). According to this strategy, the isolated HSCs are basically a pool of cells with different degrees of damage accumulation (according to, for example, donor's age and lifestyle). By up-regulating tumor suppression responses, the probability of detecting such damage and, consequently, of eliminating damaged cells from the HSC pool by senescence or apoptosis, increases. Importantly, there is no telomerase

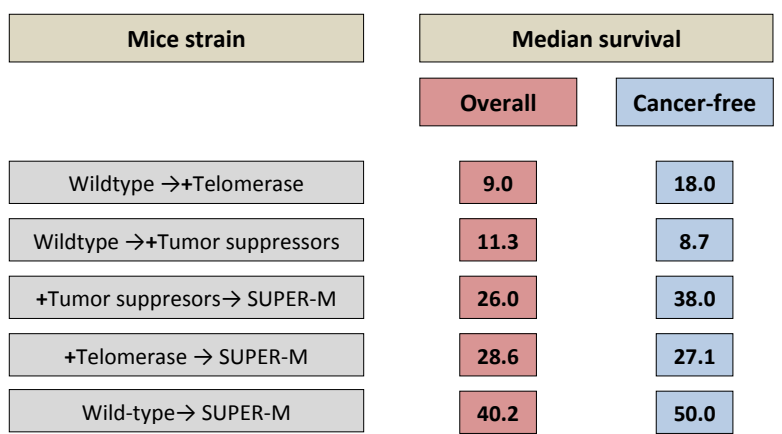

Figure 1: Wildtype: Sp53 mice. +Tumor suppressors: Sp53/Sp16/SArf mice. +Telomerase: Sp53/ TgTert. SUPER-M: Sp53/Sp16/SArf/TgTert. The values in each cell represent the median increase in survival, comparing the two strains (reference strain $\rightarrow$ group of interest). The values for the "Wildtype $\rightarrow++$ Tumor suppressors" and "+Telomerase $\rightarrow$ SUPER-M" comparisons were calculated based on the values for the other comparisons. Blue boxes: overall median survival. Red boxes: cancer-free median survival.

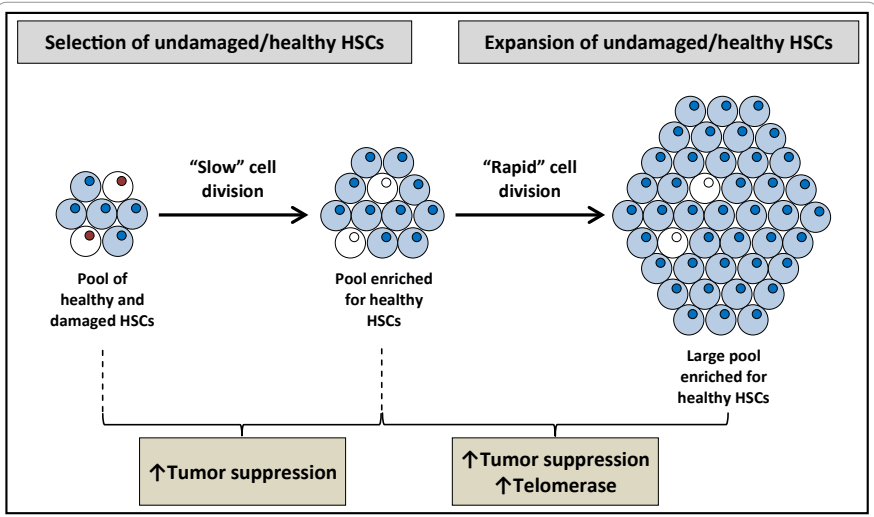

Figure 2: The figure is a simplified illustration of the two-step strategy to boost HSCT by culturing HSCs under up-regulation of telomerase activity and tumor suppression responses. Blue cells: healthy cells. Red cells: damaged cells. Colorless cells: damaged cells that have been sensed and cleared from the HSC pool by the tumor suppression machinery.

up-regulation in this step, which reduces the chances that telomerase activity confers apoptosis resistance to some stress markers present in the HSC pool (since damaged HSCs are likely to be sensed and eliminated by the tumor suppression machinery). This process results in a HSC pool enriched for healthy cells, which can be expanded by serial passages under up-regulation of telomerase activity and tumor suppression responses, in order to avoid undesirable HSC telomere shortening (or even promote HSC telomere lengthening) and protect the cell pool from accumulating stress markers (given the evidence for protective roles of both telomerase activity and tumor suppression responses).

\section{Conclusions: Applications, Limitations and Perspectives}

The relevance of the proposed strategy lies on the importance of HSCT and to the plausible generalizability of the benefits of this approach to culture other types of cells (as well as to other applications using HSCs). HSCT is the first form of stem cell therapy used in human medicine [65], and its current applications are not limited to myeloma or leukemia patients $[66,67]$, with therapeutic uses for auto-immune and cardiovascular disease $[68,69]$. HSCT requires isolation of HSCs, but does not select for healthy cells [70]. The proposed strategy allows expanding isolated HSCs in a selective condition that enriches for healthy cells, thus benefiting HSCT both quantitatively and qualitatively. Moreover, the strategy may also enlarge the range of potential donors. For instance, HSCT using HSCs from old donors are known to increase the risk of graft-versus-host disease and decrease probability of survival $[71,72]$. Considering that DNA damage accumulation and telomere shortening are aging hallmarks (as already discussed here), it is plausible to hypothesize that applying the two-step strategy would alleviate HSCT difficulties associated with old donors. In this regard, telomere shortening has been associated with other HSCT issues, including graft failure [73]. This is an important consideration given the advantages of receiving HSCs from a close relative (such as a sibling or a parent) regarding graft-versus-host disease risk [74], since it might well be the case that the closest relatives are in the risk age group regarding HSCs donation. Moreover, a recent study suggests that long-term immune reconstitution after haploidentical HSCT (which is a good alternative for patients lacking a human leukocyte antigen-matched donor [75]) largely depends on de novo T cell production, with implications for telomere length since naive-enriched $\mathrm{CD} 4^{+} \mathrm{T}$ cell populations of HSCT recipients presented shorter telomeres than age-matched controls, 
Citation: Hartwig FP (2013) Up-Regulating Telomerase and Tumor Suppression: A Two-Step Strategy to Boost Hematopoietic Stem Cell Transplantation. J Stem Cell Res Ther S3:003. doi:10.4172/2157-7633.S3-003

although telomere length was similar in differentiated $\mathrm{CD} 4^{+}$and $\mathrm{CD} 8^{+}$ T cells [76].

In spite of the proposed strategy being potentially beneficial for HSCT and other cell therapy applications, it is important to note some of its limitations. First, there are limitations of HSCT that are unlikely to be alleviated by enriching the HSC pool for healthy cells. For instance, although aplastic anemia (a condition associated with short telomeres) can be treated by allogeneic stem cell transplant in humans [23], a recent study on the effectiveness of allogeneic HSCT in 34 dyskeratosis congenita patients reported a 10 -year probability of survival of $30 \%$, with ten deaths occurring until 4 months after HSCT due to graft failure (in 6 cases) or other transplant-related complications [77]. Although 9 of these patients had mismatched related or unrelated donors, an additional possibility comes from studies that showed that telomere dysfunction in telomerase-deficient mice induces alterations of the hematopoietic environment, resulting in HSC impairments (including HSC function, engraftment, and $\mathrm{B}$ and $\mathrm{T}$ lymphopoiesis) independently of the telomere length of HSCs themselves [78-80]. These studies suggest that, for patients with particularly short telomeres (e.g., very old patients or cases of telomere syndromes), the engraftment might be complicated due to the recipient's hematopoietic environment, thus reducing the importance of the quality of the HSCs used for transplantation. Another important consideration is related to DNA damage accumulation of HSCs. There are components other than surveillance mechanisms that compose the DNA maintenance machinery, such as direct DNA damage repair and inactivation or interception of mutagenic molecules before they cause DNA damage [49] and, as discussed here, the former has been strongly evidenced to occur in HSCs as a causal factor of aging. Nevertheless, these two limitations are unlikely to undermine the usefulness of the proposed strategy, since using healthier HSC for HSCT would be beneficial for several applications and the results of the SUPER-M mice study indicate that up-regulating telomerase and tumor suppression (without specifically targeting other pathways associated with DNA maintenance) are sufficient to reduce/delay the occurrence of aging phenotypes at no (significant) increase in cancer risk.

Although the proposed model follows logically from the current knowledge regarding telomere biology and DNA damage accumulation in HSCs, it has not been experimentally tested to date. An important perspective would be to simulate (in mice, for example) different conditions of common application of HSCT in order to verify whether or not (and to what extend) the two-step strategy actually provides better results than standard HSCT. One of the most interesting situations would be to compare the effect of the proposed strategy on HSCT having donors that are likely to have less healthy HSCs, such as late-generation telomerase-deficient mice that had telomerase restored (by using a Cre-LoxP recombination system, for example) or mice subjected to different types of unhealthy factors (e.g., high-fat diet). Another critical perspective concerns the methods for up-regulating telomerase and tumor suppression responses, since temporary modulators (such as molecules added to the culture medium) would be preferred over approaches such as lentivirus-mediated transfection. In this regard, chemical modulators of telomerase activity [81-83] and of p53 (a major tumor suppressor protein [84], encoded by TP53 in humans and Tp53 in mice - GeneEntrezIDs: 7157 and 22059, respectively) activity [85] have been identified and studied, showing in vitro and in vivo activity. It is important to consider, however, the of using genetically engineering HSCs in order to greatly up-regulate telomerase and tumor suppression responses for HSCT procedures of more extreme cases, although the risk of such procedure is yet to be investigated. In conclusion, the proposed two-step strategy is a plausible method to enrich the HSC pool for healthy cells, which may have important beneficial impacts - quantitatively and qualitatively for HSCT.

\section{References}

1. Beaglehole R, Bonita R, Alleyne G, Horton R, Li L, et al. (2011) UN High-Leve Meeting on Non-Communicable Diseases: addressing four questions. Lancet 378: 449-455.

2. Ho AD, Wagner W, Mahlknecht U (2005) Stem cells and ageing. The potential of stem cells to overcome age-related deteriorations of the body in regenerative medicine. EMBO Rep S35-38.

3. Harley CB, Vaziri H, Counter CM, Allsopp RC (1992) The telomere hypothesis of cellular aging. Exp Gerontol 27: 375-382.

4. Moyzis RK, Buckingham JM, Cram LS, Dani M, Deaven LL, et al. (1988) A highly conserved repetitive DNA sequence, (TTAGGG)n, present at the telomeres of human chromosomes. Proc Natl Acad Sci U S A 85: 6622-6626.

5. de Lange $T(2005)$ Shelterin: the protein complex that shapes and safeguards human telomeres. Genes Dev 19: 2100-2110.

6. Palm W, de Lange $T$ (2008) How shelterin protects mammalian telomeres Annu Rev Genet 42: 301-334.

7. Olovnikov AM (1973) A theory of marginotomy. The incomplete copying of template margin in enzymic synthesis of polynucleotides and biological significance of the phenomenon. J Theor Biol 41: 181-190.

8. Deng Y, Chan SS, Chang S (2008) Telomere dysfunction and tumour suppression: the senescence connection. Nat Rev Cancer 8: 450-458

9. Greider CW, Blackburn EH (1985) Identification of a specific telomere terminal transferase activity in Tetrahymena extracts. Cell 43: 405-413.

10. Greider CW, Blackburn EH (1987) The telomere terminal transferase of Tetrahymena is a ribonucleoprotein enzyme with two kinds of primer specificity. Cell 51: 887-898

11. Abbott A (2009) Chromosome protection scoops Nobel. Nature 461: 706-707.

12. Kim NW, Piatyszek MA, Prowse KR, Harley CB, West MD, et al. (1994) Specific association of human telomerase activity with immortal cells and cancer. Science 266: 2011-2015

13. Wright WE, Piatyszek MA, Rainey WE, Byrd W, Shay JW (1996) Telomerase activity in human germline and embryonic tissues and cells. Dev Genet 18: 173-179.

14. Flores I, Benetti R, Blasco MA (2006) Telomerase regulation and stem cell behaviour. Curr Opin Cell Biol 18: 254-260.

15. Chiu CP, Dragowska W, Kim NW, Vaziri H, Yui J, et al. (1996) Differentia expression of telomerase activity in hematopoietic progenitors from adult human bone marrow. Stem Cells 14: 239-248.

16. Vaziri H, Dragowska W, Allsopp RC, Thomas TE, Harley CB, et al. (1994) Evidence for a mitotic clock in human hematopoietic stem cells: loss of telomeric DNA with age. Proc Natl Acad Sci U S A 91: 9857-9860

17. Belair CD, Yeager TR, Lopez PM, Reznikoff CA (1997) Telomerase activity: a biomarker of cell proliferation, not malignant transformation. Proc Natl Acad Sci U S A 94: 13677-13682.

18. Shay JW, Bacchetti S (1997) A survey of telomerase activity in human cancer Eur J Cancer 33: 787-791.

19. Feldser DM, Hackett JA, Greider CW (2003) Telomere dysfunction and the initiation of genome instability. Nat Rev Cancer 3: 623-627.

20. Hartwig FP, Collares T (2013) Telomere dysfunction and tumor suppression responses in dyskeratosis congenita: Balancing cancer and tissue renewal impairment. Ageing Res Rev 12: 642-652.

21. Metcalf D (1988)The Molecular Control of Blood Cells. Harvard University Press.

22. Muller-Sieburg CE, Cho RH, Thoman M, Adkins B, Sieburg HB (2002) Deterministic regulation of hematopoietic stem cell self-renewal and differentiation. Blood 100: 1302-1309.

23. Armanios M, Blackburn EH (2012) The telomere syndromes. Nat Rev Genet 13: $693-704$. 
Citation: Hartwig FP (2013) Up-Regulating Telomerase and Tumor Suppression: A Two-Step Strategy to Boost Hematopoietic Stem Cell Transplantation. J Stem Cell Res Ther S3:003. doi:10.4172/2157-7633.S3-003

24. Dokal I (2011) Dyskeratosis congenita. Hematology Am Soc Hematol Educ Program 2011: 480-486.

25. Kirwan M, Dokal I (2009) Dyskeratosis congenita, stem cells and telomeres. Biochim Biophys Acta 1792: 371-379

26. Armanios M (2013) Telomeres and age-related disease: how telomere biology informs clinical paradigms. J Clin Invest 123: 996-1002.

27. Hao LY, Armanios M, Strong MA, Karim B, Feldser DM, et al. (2005) Short telomeres, even in the presence of telomerase, limit tissue renewal capacity. Cell 123: 1121-1131.

28. Yamaguchi H, Calado RT, Ly H, Kajigaya S, Baerlocher GM, et al. (2005) Mutations in TERT, the gene for telomerase reverse transcriptase, in aplastic anemia. N Engl J Med 352: 1413-1424.

29. Parry EM, Alder JK, Qi X, Chen JJ, Armanios M (2011) Syndrome complex of bone marrow failure and pulmonary fibrosis predicts germline defects in telomerase. Blood 117: 5607-5611.

30. Allsopp RC, Morin GB, DePinho R, Harley CB, Weissman IL (2003) Telomerase is required to slow telomere shortening and extend replicative lifespan of HSCs during serial transplantation. Blood 102: 517-520

31. Goldman FD, Aubert G, Klingelhutz AJ, Hills M, Cooper SR, et al. (2008) Characterization of primitive hematopoietic cells from patients with dyskeratosis congenita. Blood 111: 4523-4531.

32. Fogarty PF, Yamaguchi H, Wiestner A, Baerlocher GM, Sloand E, et al. (2003) Late presentation of dyskeratosis congenita as apparently acquired aplastic anaemia due to mutations in telomerase RNA. Lancet 362: 1628-1630.

33. Rossi DJ, Bryder D, Seita J, Nussenzweig A, Hoeijmakers J, et al. (2007) Deficiencies in DNA damage repair limit the function of haematopoietic stem cells with age. Nature 447: 725-729.

34. Allsopp RC, Cheshier S, Weissman IL (2001) Telomere shortening accompanies increased cell cycle activity during serial transplantation of hematopoietic stem cells. J Exp Med 193: 917-924.

35. Thornley I, Sutherland R, Wynn R, Nayar R, Sung L, et al. (2002) Early hematopoietic reconstitution after clinical stem cell transplantation: evidence for stochastic stem cell behavior and limited acceleration in telomere loss. Blood 99: 2387-2396.

36. Allsopp RC, Cheshier S, Weissman IL (2002) Telomerase activation and rejuvenation of telomere length in stimulated $T$ cells derived from serially transplanted hematopoietic stem cells. J Exp Med 196: 1427-1433.

37. Allsopp RC, Weissman IL (2002) Replicative senescence of hematopoietic stem cells during serial transplantation: does telomere shortening play a role? Oncogene 21: 3270-3273.

38. Effros RB, Globerson A (2002) Hematopoietic cells and replicative senescence. Exp Gerontol 37: 191-196.

39. Piacibello W, Gammaitoni L, Pignochino Y (2005) Proliferative senescence in hematopoietic stem cells during ex-vivo expansion. Folia Histochem Cytobiol 43: 197-202.

40. Zimmermann S, Glaser S, Ketteler R, Waller CF, Klingmuller U, et al. (2004) Effects of telomerase modulation in human hematopoietic progenitor cells. Stem Cells 22: 741-749.

41. Zimmermann S, Martens UM (2008) Telomeres, senescence, and hematopoietic stem cells. Cell Tissue Res 331: 79-90.

42. Lopez-Otin C, Blasco MA, Partridge L, Serrano M, Kroemer G (2013) The hallmarks of aging. Cell 153: 1194-1217.

43. Best BP (2009) Nuclear DNA damage as a direct cause of aging. Rejuvenation Res 12: 199-208.

44. Freitas AA, de Magalhaes JP (2011) A review and appraisal of the DNA damage theory of ageing. Mutat Res 728: 12-22.

45. Nijnik A, Woodbine L, Marchetti C, Dawson S, Lambe T, et al. (2007) DNA repair is limiting for haematopoietic stem cells during ageing. Nature 447: 686690.

46. Rossi DJ, Seita J, Czechowicz A, Bhattacharya D, Bryder D, et al. (2007) Hematopoietic stem cell quiescence attenuates DNA damage response and permits DNA damage accumulation during aging. Cell Cycle 6: 2371-2376

47. Niedernhofer LJ (2008) DNA repair is crucial for maintaining hematopoietic stem cell function. DNA Repair (Amst) 7: 523-529.
48. Goodarzi AA, Jeggo PA (2013) The repair and signaling responses to DNA double-strand breaks. Adv Genet 82: 1-45

49. Hanahan D, Weinberg RA (2011) Hallmarks of cancer: the next generation Cell 144: 646-674.

50. Hartwig FP, Nedel F, Collares TV, Tarquinio SB, Nor JE, et al. (2012) Telomeres and tissue engineering: the potential roles of TERT in VEGFmediated angiogenesis. Stem Cell Rev 8: 1275-1281.

51. Kang HJ, Choi YS, Hong SB, Kim KW, Woo RS, et al. (2004) Ectopic expression of the catalytic subunit of telomerase protects against brain injury resulting from ischemia and NMDA-induced neurotoxicity. J Neurosci 24: 1280-1287.

52. Armstrong L, Saretzki G, Peters H, Wappler I, Evans J, et al. (2005) Overexpression of telomerase confers growth advantage, stress resistance, and enhanced differentiation of ESCs toward the hematopoietic lineage. Stem Cells 23: 516-529.

53. Masutomi K, Possemato R, Wong JM, Currier JL, Tothova Z, et al. (2005) The telomerase reverse transcriptase regulates chromatin state and DNA damage responses. Proc Natl Acad Sci U S A 102: 8222-8227.

54. Park JI, Venteicher AS, Hong JY, Choi J, Jun S, et al. (2009) Telomerase modulates Wnt signalling by association with target gene chromatin. Nature 460: 66-72.

55. Indran IR, Hande MP, Pervaiz S (2011) hTERT overexpression alleviates intracellular ROS production, improves mitochondrial function, and inhibits ROS-mediated apoptosis in cancer cells. Cancer Res 71: 266-276.

56. Singhapol C, Pal D, Czapiewski R, Porika M, Nelson G, et al. (2013) Mitochondrial telomerase protects cancer cells from nuclear DNA damage and apoptosis. PLoS One 8: e52989.

57. Jackson SP, Bartek J (2009) The DNA-damage response in human biology and disease. Nature 461: 1071-1078.

58. Kastan MB (2008) DNA damage responses: mechanisms and roles in human disease: 2007 G.H.A. Clowes Memorial Award Lecture. Mol Cancer Res 6: 517-524.

59. Sigal A, Rotter V (2000) Oncogenic mutations of the p53 tumor suppressor: the demons of the guardian of the genome. Cancer Res 60: 6788-6793.

60. Barnes DE, Lindahl T (2004) Repair and genetic consequences of endogenous DNA base damage in mammalian cells. Annu Rev Genet 38: 445-476.

61. He S, Nakada D, Morrison SJ (2009) Mechanisms of stem cell self-renewal. Annu Rev Cell Dev Biol 25: 377-406.

62. Tomas-Loba A, Flores I, Fernandez-Marcos PJ, Cayuela ML, Maraver A, et al. (2008) Telomerase reverse transcriptase delays aging in cancer-resistant mice. Cell 135: 609-622.

63. Donate LE, Blasco MA (2010) Telomeres in cancer and ageing. Philos Trans R Soc B Biol Sci 366: 76-84.

64. Flores I, Blasco MA (2010) The role of telomeres and telomerase in stem cell aging. FEBS Letters 584: 3826-3830.

65. Thomas ED, Lochte HL Jr, Lu WC, Ferrebee JW (1957) Intravenous infusion of bone marrow in patients receiving radiation and chemotherapy. $\mathrm{N}$ Engl J Med 257: 491-496.

66. Blade J, Samson D, Reece D, Apperley J, Bjorkstrand B, et al. (1998) Criteria for evaluating disease response and progression in patients with multiple myeloma treated by high-dose therapy and haemopoietic stem cell transplantation. Myeloma Subcommittee of the EBMT. European Group for Blood and Marrow Transplant. Br J Haematol 102: 1115-1123.

67. Pavletic SZ, Khouri IF, Haagenson M, King RJ, Bierman PJ, et al. (2005) Unrelated donor marrow transplantation for B-cell chronic lymphocytic leukemia after using myeloablative conditioning: results from the Center for International Blood and Marrow Transplant research. J Clin Oncol 23: 5788-5794.

68. Tyndall A, Fassas A, Passweg J, Ruiz de Elvira C, Attal M, et al. (1999) Autologous haematopoietic stem cell transplants for autoimmune diseasefeasibility and transplant-related mortality. Autoimmune Disease and Lymphoma Working Parties of the European Group for Blood and Marrow Transplantation, the European League Against Rheumatism and the International Stem Cel Project for Autoimmune Disease. Bone Marrow Transplant 24: 729-734.

69. Burt RK, Loh Y, Pearce W, Beohar N, Barr WG, et al. (2008) Clinical applications of blood-derived and marrow-derived stem cells for nonmalignant diseases. JAMA 299: 925-936. 
Citation: Hartwig FP (2013) Up-Regulating Telomerase and Tumor Suppression: A Two-Step Strategy to Boost Hematopoietic Stem Cell Transplantation. J Stem Cell Res Ther S3:003. doi:10.4172/2157-7633.S3-003

70. Lo Celso C, Scadden D (2007) Isolation and transplantation of hematopoietic stem cells (HSCs). J Vis Exp 157

71. Doney K, Fisher LD, Appelbaum FR, Buckner CD, Storb R, et al. (1991) Treatment of adult acute lymphoblastic leukemia with allogeneic bone marrow transplantation. Multivariate analysis of factors affecting acute graft-versushost disease, relapse, and relapse-free survival. Bone Marrow Transplant 7: 453-459.

72. Popplewell LL, Forman SJ (2002) Is there an upper age limit for bone marrow transplantation? Bone Marrow Transplant 29: 277-284.

73. Awaya N, Baerlocher GM, Manley TJ, Sanders JE, Mielcarek M, et al. (2002) Telomere shortening in hematopoietic stem cell transplantation: a potential mechanism for late graft failure? Biol Blood Marrow Transplant 8: 597-600.

74. Petersdorf EW (2008) Optimal HLA matching in hematopoietic cell transplantation. Curr Opin Immunol 20: 588-593.

75. 75. Huang XJ (2008) Current status of haploidentical stem cell transplantation for leukemia.J Hematol Oncol 1: 27

76. Azevedo RI, Soares MV, Albuquerque AS, Tendeiro R, Soares RS, et al. (2013) Long-term immune reconstitution of naive and memory t cell pools after haploidentical hematopoietic stem cell transplantation. Biol Blood Marrow Transplant 19: 703-712.

77. Gadalla SM, Sales-Bonfim C, Carreras J, Alter BP, Antin JH, et al. (2013) Outcomes of allogeneic hematopoietic cell transplant in patients with dyskeratosis congenita. Biol Blood Marrow Transplant 19: 1238-1243.
78. Ju Z, Jiang H, Jaworski M, Rathinam C, Gompf A, et al. (2007) Telomere dysfunction induces environmental alterations limiting hematopoietic stem cell function and engraftment. Nat Med 13: 742-747.

79. Song Z, Wang J, Guachalla LM, Terszowski G, Rodewald HR, et al. (2010) Alterations of the systemic environment are the primary cause of impaired $B$ and T lymphopoiesis in telomere-dysfunctional mice. Blood 115: 1481-1489.

80. Song Z, Zhang J, Ju Z, Rudolph KL (2012) Telomere dysfunctional environment induces loss of quiescence and inherent impairments of hematopoietic stem cell function. Aging Cell 11: 449-455.

81. Effros RB (2009) Kleemeier Award Lecture 2008--the canary in the coal mine: telomeres and human healthspan.J Gerontol A Biol Sci Med Sci 64: 511-515.

82. Bernardes de Jesus B, Schneeberger K, Vera E, Tejera A, Harley CB, et al. (2011) The telomerase activator TA-65 elongates short telomeres and increases health span of adult/old mice without increasing cancer incidence. Aging Cell 10: 604-621.

83. Harley CB, Liu W, Blasco M, Vera E, Andrews WH, et al. (2011) A natura product telomerase activator as part of a health maintenance program Rejuvenation Res 14: 45-56.

84. Lane DP (1992) Cancer. p53, guardian of the genome. Nature 358: 15-16.

85. Vassilev LT, Vu BT, Graves B, Carvajal D, Podlaski F, et al. (2004) In vivo activation of the p53 pathway by small-molecule antagonists of MDM2.Science 303: 844-848.
This article was originally published in a special issue, Hematopoietic stem cell transplantation handled by Editor(s). Dr. Porrata Luis F, Mayo Clinic Transplant Center, USA 